\title{
Lodo proveniente da estação de tratamento de água do município de Leopoldina, MG, para aproveitamento na indústria de cerâmica vermelha Parte I: caracterização do lodo
}

\author{
Waterworks waste (sludge) of the Leopoldina, \\ $M G$, region aiming its use in the red ceramic industry. \\ Part I: characterization of the sludge
}

\footnotetext{
${ }^{1,3}$ Departamento de Design-Universidade do Estado de Minas Gerais - UEMG CP: 36500 - 000, Ubá, MG e-mail: bruno.pinheiro@uemguba.edu.br

1,2Departamento de Engenharia - Faculdades Integradas de Cataguases/Grupo UNIS - FIC/UNIS CP: 36770-000, Cataguases, $\mathrm{MG}$

e-mail: deborap.souza@hotmail.com
}

\section{RESUMO}

O objetivo do presente trabalho foi avaliar as características mineralógica e físico-químicas do resíduo lodo de ETA do município de Leopoldina, MG, visando seu aproveitamento na indústria de cerâmica vermelha. Foram realizados ensaios de difração de raios $\mathrm{X}$, espectrometria de absorção atômica, fluorescência de raios $\mathrm{X}$, análise térmica (ATD/TG), granulometria, análise morfológica e propriedades plásticas. Os resultados obtidos indicaram que o resíduo lodo de ETA tem potencial para ser incorporado em massas argilosas para a fabricação de cerâmica vermelha.

Palavras-chave: caracterização, cerâmica vermelha, resíduo de ETA.

\section{ABSTRACT}

The aim of this work was evaluate the mineralogical and physical-chemical characteristics of the waste (sludge) from the waterworks of the Leopoldina, MG, region for their use in red ceramic industry. The waste (sludge) was submitted to X-ray diffraction, atomic absorption spectrometry, X-ray fluorescence, thermal analysis and plasticity. The results showed that the ETA waste has a potential to be mixed to the raw material for the manufacture of red ceramics.

Keywords: characterization, red ceramic, waterworks waste.

\section{INTRODUÇÃO}

O panorama do saneamento urbano mundial, demanda a responsabilidade de garantir a qualidade de vida de suas populações [1]. A água é de vital importância para os seres humanos, para a flora e para a fauna. Além disso, apresenta do ponto de vista industrial uma ampla variedade de aplicações tais como matéria-prima, solvente, fluido de refrigeração, meio de transporte, agente de limpeza, fonte de vapor, entre outros. Praticamente todos os locais de captação de água estão fora dos padrões de potabilidade exigidos. Sendo assim, torna-se indispensável o tratamento da água []ㅡ.

As Estações de Tratamento de Águas assumem papel fundamental para a obtenção de água tratada de qualidade com características físico-químicas e biológicas de acordo com os padrões de potabilidades exigidos pelo Ministério da Saúde [1]. No Brasil existem cerca de 7.500 estações de tratamento de água (ETA). Destas, aproximadamente $75 \%$, utilizam o processo convencional para tratamento da água. Este processo consiste nas operações de coagulação, floculação, decantação e filtração para clarificação da água, seguida de correção de pH, desinfecção e, em alguns casos, de fluoretação [즈, $\underline{4}]$.

O sistema de abastecimento de água no município de Leopoldina, MG, é operado e mantido pela 
Companhia de Saneamento de Minas Gerais - COPASA, empresa de âmbito estadual, através do sistema operacional local, subordinado ao Distrito operacional de Leopoldina, que por sua vez é subordinado a Superintendência do Sudeste. Assim como na maioria dos municípios brasileiros, a ETA do município de Leopoldina, é do tipo convencional. Ela foi construída em concreto armado, possuindo um medidor Parshall, cinco floculadores mecanizados, dois decantadores retangulares convencionais e quatro filtros rápidos. A captação de água é do tipo superficial, tendo como manancial o rio Pirapitinga e capacidade para tratamento de 150 1/s. São utilizados os seguintes produtos químicos: sulfato de alumínio líquido como coagulante, cal hidratada para correção do pH, cloro gasoso na desinfecção e flúor []].

O processo convencional de tratamento de água tem como objetivo principal retirar impurezas presentes na água. Tais impurezas são provenientes, principalmente, da formação geológica do manancial e de atividades poluidoras ativas inseridas na área de influência. Neste sistema obtem-se água como produto final e um subproduto que recebe o nome de lodo de Estação de Tratamento de Água (lodo de ETA). Do ponto de vista ambiental, o lodo de ETA é classificado como resíduo Classe IIA - Não Inerte [6]. Ele é formado por sólidos e precipitados químicos, constituindo uma massa de partículas orgânicas e inorgânicas, densa e viscosa. Suas características qualitativas e quantitativas podem sofrer variações de acordo com alguns fatores tais como gerenciamento do processo de tratamento, métodos de operação do sistema, periodicidade de limpeza dos decantadores e filtros, dosagem dos produtos químicos utilizados, o uso e a ocupação do solo da área da bacia hidrográfica e o ciclo hidrológico característico regional [7]. Por ser um resíduo sólido não inerte, o lodo de ETA deve ser devidamente tratado e disposto de forma adequada para que não provoque danos ao meio ambiente, uma vez que contêm concentrações elevadas de elementos químicos ( $\mathrm{Al}, \mathrm{Fe}, \mathrm{Ti}, \mathrm{Mg}$, entre outros) $[\underline{7}, \underline{8}]$.

Muitos municípios brasileiros geram enormes quantidades de resíduo lodo de ETA. Além disso, fazem a disposição final deste resíduo de maneira inadequada, lançando-o em cursos d'água. Este lançamento pode ser feito sob certas condições específicas e depende da permissão dos órgãos ambientais. Esta autorização é função das características e do volume do curso d'água. Existem restrições a esta prática devido à possibilidade de se alterar a biota aquática e de se causar degradação da água e sedimentos, pela presença de contaminantes nos coagulantes utilizados [9]. Assim, estes fatores podem contribuir para o aumento da problemática de geração de resíduo lodo de ETA e seu destino final adequado ao controle ambiental técnicolegal da atualidade, a qual é uma questão que necessita ser solucionada [2].

A indústria de cerâmica vermelha pode contribuir de forma significativa para absorver vários tipos de resíduos poluentes [4]. De acordo com a literatura [10], diversos trabalhos têm sido desenvolvidos relacionados à incorporação de vários tipos de resíduos poluentes em massas argilosas para a fabricação de produtos de cerâmica vermelha. Dentre os vários resíduos investigados tem-se: resíduos da indústria de rochas ornamentais, resíduo do setor siderúrgico, resíduo de boro, resíduo de curtume. Tem-se ainda: borra de petróleo [11], lama galvânica gerada por indústria de galvanoplastia [12], lodo da estação de tratamento de efluente de indústria de revestimento cerâmico [13], entre outros. Isto se deve ao fato de que as massas argilosas utilizadas são de natureza heterogênea. Geralmente estas massas são constituídas por matérias-primas plásticas e não-plásticas com ampla variação física, química e mineralógica. Isto permite que as massas argilosas utilizadas em cerâmica vermelha sejam tolerantes e permitam a presença de vários tipos de materiais residuais, mesmo em porcentagens significantes $[\underline{2}, \underline{14}]$. Além disso, a etapa de sinterização (queima) que ocorre durante o processamento dos produtos cerâmicos pode promover a inertização dos componentes tóxicos dos resíduos. Isto pode ser feito por volatilização, transformação química e estabilização na fase vítrea (fase amorfa), a qual se forma durante a sinterização dos produtos cerâmicos. E ainda, a incorporação dos resíduos pode contribuir para o melhoramento do processamento cerâmico, para aumentar a qualidade dos produtos, para reduzir o gasto energético na etapa de sinterização, bem como reduzir o consumo de argilas, principal matéria-prima do setor de cerâmica vermelha, sendo um recurso natural não renovável [15].

Um dos resíduos que apresentam potencial para serem reciclados em cerâmica vermelha são os lodos gerados nas Estações de Tratamento de Água (ETA). De fato, alguns trabalhos reportados na literatura têm mostrado que é possível a reciclagem, através da incorporação do resíduo lodo de ETA em massas argilosas para cerâmica vermelha $[\underline{1}, \underline{4}, \underline{6}-\underline{9}, \underline{15}-\underline{17}]$. Para esta aplicação (incorporação), é de fundamental importância estudar as características do resíduo lodo de ETA a ser incorporado. Assim, de forma a contribuir com outros trabalhos como [2, $\underline{15}$ ], no sentido de se conhecer e estudar as características do lodo de ETA para a incorporação em massas argilosas para cerâmica vermelha, o objetivo principal deste trabalho é a caracterização físico-químico-mineralógica de uma amostra de resíduo sólido de lodo de ETA proveniente do município de Leopoldina, MG, visando a sua utilização em massas cerâmicas para a fabricação de produtos de cerâmica vermelha. Para a realização de tal caracterização são utilizados os seguintes métodos de análise: espectrosco- 
pia de absorção atômica, fluorescência de raios X (FRX), perda ao fogo (PF), difração de raios X (DRX), análise térmica diferencial (ATD), análise termogravimétrica (ATG), microscopia ótica e peneiramento a úmido.

\section{MATERIAIS E MÉTODOS}

O resíduo utilizado neste trabalho foi coletado na Estação de Tratamento de Água do município de Leopoldina, MG. A amostra do resíduo bruto apresenta-se na forma de lodo. O resíduo ficou durante $72 \mathrm{~h}$ em processo de decantação em um recipiente plástico para facilitar a retirada do excesso de água. Em seguida, o resíduo foi submetido a um processo de secagem em estufa de laboratório a $110^{\circ} \mathrm{C}$ por $24 \mathrm{~h}$ e destorroado, constituindo-se na amostra de trabalho, a qual foi denominada de resíduo (lodo) de ETA.

A composição química da amostra foi determinada por espectrometria de absorção atômica e fluorescência de raios X (FRX).

A análise mineralógica qualitativa da amostra de resíduo foi determinada por difração de raios $\mathrm{X}$ (DRX) (DifratômetroBruker - D8) utilizando radiação $\mathrm{K} \alpha$ do $\mathrm{Cu}\left(\lambda=1,54 \AA\right.$ Å), sob ângulo $2 \theta$ de $2^{\circ}$ até $80^{\circ}$, com passo de 0,02 . Os experimentos de análise térmica diferencial (ATD) e análise termogravimétrica (ATG) foram realizados em atmosfera de ar da temperatura ambiente $\left(\approx 25^{\circ} \mathrm{C}\right)$ até $1200{ }^{\circ} \mathrm{C}$, com taxa de aquecimento de $10^{\circ} \mathrm{C} / \mathrm{min}$. Para estes experimentos foi utilizado um analisador térmico simultâneo (Netzsch modelo STA 409EP).

A distribuição granulométrica da amostra do resíduo (lodo) de ETA foi determinada por peneiramento a úmido. A massa específica real dos grãos foi determinada de acordo com a norma NBR 6508-84. Os limites de consistência de Atterberg foram determinados de acordo com as normas NBR 6459-84 e NBR 7180-84. A morfologia das partículas foi analisada por microscopia ótica.

\section{RESULTADOS}

A Figura 1 mostra o difratograma de raios $\mathrm{X}$ da amostra do resíduo estudado.

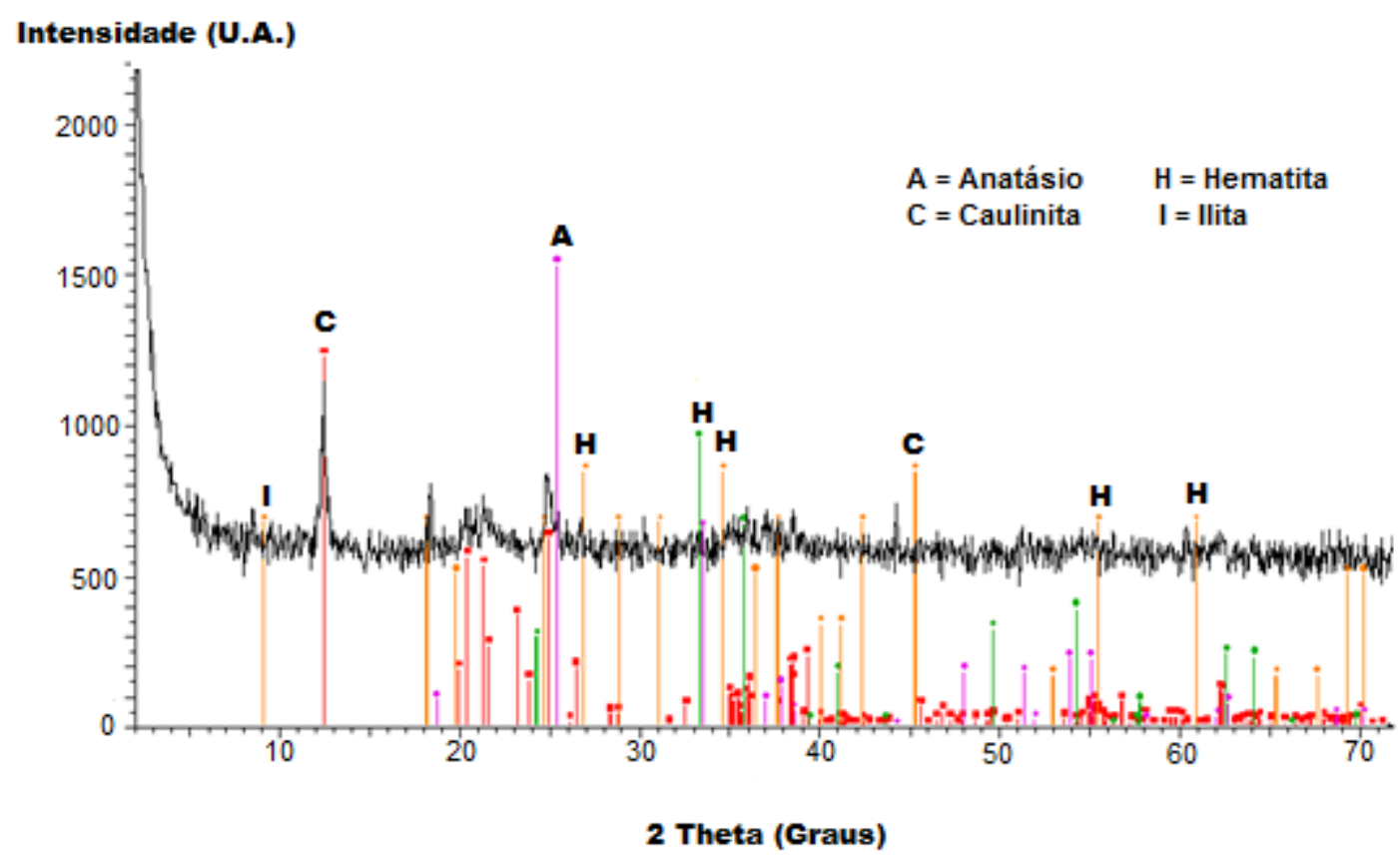

Figura 1: Difratograma de raios-X do resíduo (lodo) de ETA.

A Figura 2 apresenta as curvas de análise térmica diferencial (ATD) e análise termogravimétrica (ATG). A Tabela 1 apresenta os dados resumidos de perda de massa da amostra de resíduo analisada.

A Tabela 2 apresenta a composição química e a perda de massa (perda ao fogo - P.F) da amostra do resíduo estudado neste trabalho.

A Tabela 3 mostra a distribuição granulométrica da amostra do resíduo (lodo) de ETA estudado. A 


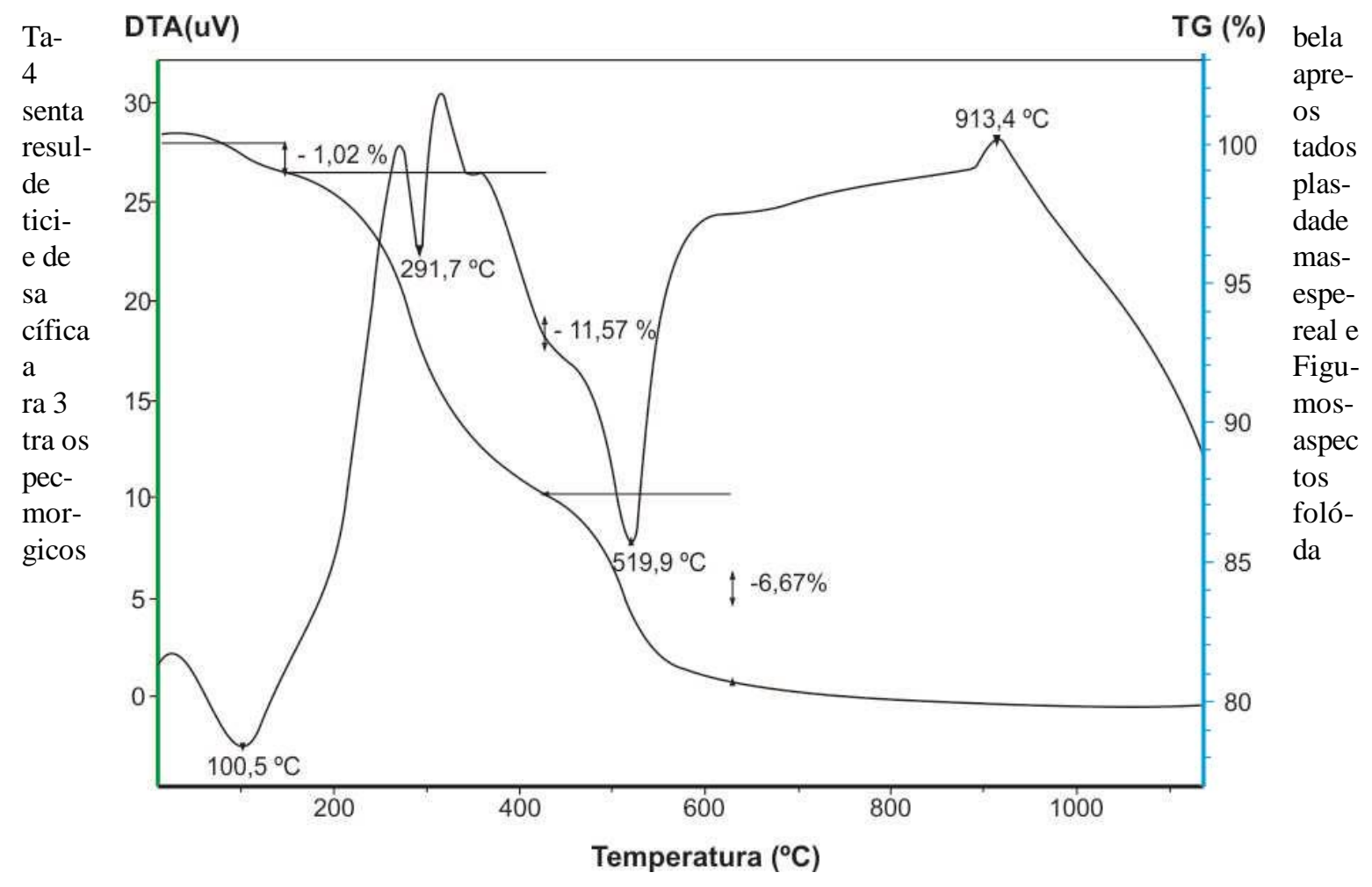

amostra de resíduo (lodo) de ETA estudada.

Figura 2: Curvas ATD/ATG do resíduo (lodo) de ETA.

Tabela 1: Resultados da ATG do resíduo (lodo) de ETA.

\begin{tabular}{l|l}
\hline TEMPERATURA (ํ) & PERDA DE MASSA (\%) \\
\hline 100,5 & 1,02 \\
\hline 291,7 & 11,57 \\
\hline 519,9 & 6,67 \\
\hline
\end{tabular}

Tabela 2: Composição química (\% em peso) do resíduo (lodo) de ETA.

\begin{tabular}{l|l}
\hline OXIDOS & RESíDUO (LODO) DE ETA \\
\hline $\mathrm{SiO}_{2}$ & 26,84 \\
\hline $\mathrm{Al}_{2} \mathrm{O}_{3}$ & 26,33 \\
\hline $\mathrm{Fe}_{2} \mathrm{O}_{3}$ & 24,00 \\
\hline $\mathrm{TiO}_{2}$ & 1,26 \\
\hline $\mathrm{CaO}$ & 0,14 \\
\hline $\mathrm{MnO}$ & 1,11 \\
\hline $\mathrm{P}_{2} \mathrm{O}_{5}$ & 0,31 \\
\hline $\mathrm{MgO}$ & 0,32 \\
\hline $\mathrm{K}_{2} \mathrm{O}$ & 0,34 \\
\hline $\mathrm{Na} 2 \mathrm{O}$ & 0,03 \\
\hline $\mathrm{P.F}$ & 19,32
\end{tabular}


PINHEIRO, B. C. A.; ESTEVÃO, G. M.; SOUZA, D. P. revista Matéria, v.19, n.3, pp. 204 -211, 2014.

Tabela 3: Distribuição granulométrica (diâmetro de partícula em $\mu \mathrm{m}$ ) do resíduo (lodo) de ETA.

\begin{tabular}{l|l}
\hline DIÂMETRO DE PARTíCULA & \% DE MASSA ACUMULADA \\
\hline$>2000$ & 0,0 \\
\hline $1000-2000$ & 0,0 \\
\hline $500-1000$ & 0,0 \\
\hline $250-500$ & 0,0 \\
\hline $125-250$ & 0,0 \\
\hline $63-125$ & 0,2 \\
\hline$<63$ & 99,8 \\
\hline
\end{tabular}

Tabela 4: Limites de Atterberg e massa específica real do resíduo (lodo) de ETA.

\begin{tabular}{l|l|l|l}
\hline $\mathbf{L}_{\mathbf{p}}(\%)$ & $\mathbf{L}_{1}(\%)$ & IP $(\%)$ & MER $\left(\mathbf{g} / \mathbf{c m}^{\mathbf{3}}\right)$ \\
\hline 49 & 71 & 22 & 2,58 \\
\hline
\end{tabular}

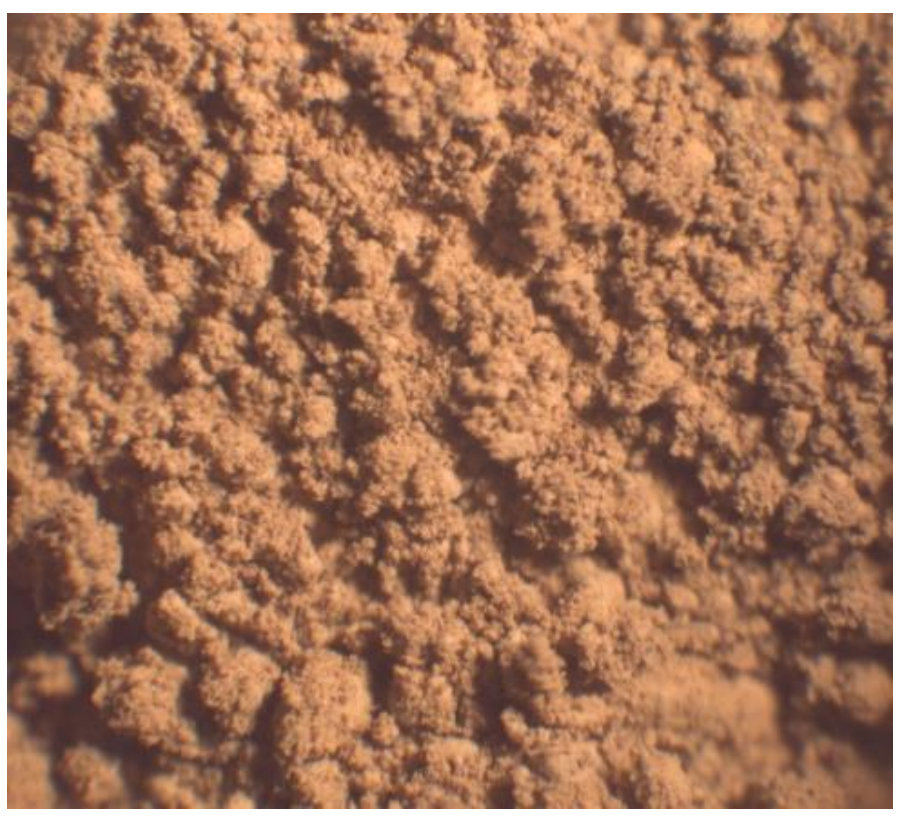

Figura 3: Aspectos morfológicos do resíduo (lodo) de ETA.

\section{DISCUSSÃO}

A partir da Figura 1 pode ser observado, principalmente, a presença de picos de difração característicos das seguintes fases cristalinas: caulinita $\left(\mathrm{Al}_{2} \mathrm{O}_{3} \cdot 2 \mathrm{SiO}_{2} \cdot 2 \mathrm{H}_{2} \mathrm{O}\right)$, principal argilomineral encontrado no lodo de ETA e hematita $\left(\mathrm{Fe}_{2} \mathrm{O}_{3}\right)$. Este resultado está de acordo com a literatura $[\underline{4}, \underline{18}]$. Há indícios da presença de ilita $\left(\mathrm{Si}_{4-}\right.$ $\left.{ }_{x} \mathrm{Al}_{\mathrm{x}}\right) \mathrm{O}_{10} \mathrm{Al}_{2-\mathrm{y}}\left(\mathrm{Mg}, \mathrm{Fe}^{11}\left(\mathrm{OH}_{2}\right) \mathrm{K}_{(\mathrm{x}+\mathrm{y})}\right.$ e anatásio $\left(\mathrm{TiO}_{2}\right)$. Contudo, a maioria dos picos de difração correspondentes a estas fases se confundem com o "background" do difratograma. Isso dificulta a interpretação, possibilitando apenas a especulação.

Em relação a curva de análise térmica diferencial (ATD) apresentada na Figura 2, pode ser observado que existem quatro eventos térmicos. Estes eventos são representados por três vales endotérmicos e um pico exotérmico. Os eventos endotérmicos ocorrem nas temperaturas de $100,5^{\circ} \mathrm{C}, 291,7{ }^{\circ} \mathrm{C}$ e $519,9^{\circ} \mathrm{C}$. O pequeno 
pico exotérmico ocorre na temperatura de $913,4^{\circ} \mathrm{C}$.

$\mathrm{O}$ primeiro vale endotérmico com máximo em $100,5^{\circ} \mathrm{C}$ corresponde à remoção de água fisicamente adsorvida na superfície das partículas de caulinita, principal argilomineral presente no resíduo lodo de ETA conforme observado na Figura 1. O segundo vale endotérmico em $291,7^{\circ} \mathrm{C}$ pode estar relacionado com a desidratação de hidróxidos existentes (gibsita e goetita) $[2,15]$. Além disso, pode estar relacionado também com a decomposição de matéria orgânica e com a presença de sulfatos, como por exemplo, o sulfato de alumínio, utilizado como coagulante no processo de tratamento da água. O sulfato de alumínio perde a água quimicamente ligada por volta de $300{ }^{\circ} \mathrm{C}$ [2]. Embora os hidróxidos de alumínio e de ferro, gibsita e goetita respectivamente, não tenham sido identificados por difração de raios X (Fig. 1), provavelmente, devido a sobreposição dos picos de difração, as curvas de ATD/TG (Fig. 2) apontam um indicativo da sua presença [15]. O terceiro vale endotérmico que ocorre com máximo na temperatura de $519,9^{\circ} \mathrm{C}$ está associado principalmente com a perda de hidroxila (água estrutural) do argilomineral caulinita, o qual se transforma em metacaulinita. Este resultado confirma a presença de caulinita (detectada em análise de DRX) no resíduo estudado. A caulinita pode ser o principal argilomineral presente nos solos da região. $\mathrm{O}$ pequeno pico exotérmico observado em torno de $913,4^{\circ} \mathrm{C}$ pode ser devido a quebra da estrutura da metacaulinita para a formação de novas fases cristalinas tais como $\gamma-\mathrm{Al}_{2} \mathrm{O}_{3}$ e/ou mulita primária [19].

Em relação à curva termogravimétrica, também apresentada na Figura 2, pode ser verificado que os eventos endotérmicos são acompanhados por um intenso processo de transferência de massa na amostra, cujos dados se encontram resumidos na Tabela 1. Pode ser verificado que a amostra de resíduo (lodo) de ETA apresenta uma perda de massa total de aproximadamente $19,26 \%$. Esta perda de massa ocorre em três etapas. Na primeira etapa, ocorre uma pequena perda de massa de aproximadamente $1,02 \%$, a qual pode estar relacionada com a liberação de umidade livre adsorvida na superfície das partículas do argilomineral caulinita [18]. Na segunda etapa, tem-se a maior perda de massa $(11,57 \%)$. Esta perda de massa pode estar relacionada com os seguintes fatores: i) liberação das moléculas de água devido a decomposição de hidróxidos tais como a gibsita e a goetita, ii) combustão de matéria orgânica e, iii) perda de água quimicamente ligada devido a presença de sulfatos, como por exemplo, o sulfato de alumínio. Na terceira etapa, pode ser observado uma perda de massa de $6,67 \%$, a qual pode estar relacionada, principalmente, com a desidroxilação do argilomineral caulinita $[18,19]$. Pode-se observar uma relação próxima entre os valores de perda ao fogo e a perda de massa total ( $19,33 \%$ e $19,26 \%$, respectivamente). A pequena diferença nos valores pode estar relacionada com a distorção da umidade livre que fica adsorvida na superfície das partículas do argilomineral caulinita presente no resíduo estudado. A curva TG foi obtida a partir da temperatura ambiente e a perda ao fogo é sempre determinada com a amostra seca em $110^{\circ} \mathrm{C}$. Os resultados obtidos até aqui são de grande importância, pois mostram que o resíduo (lodo) de ETA estudado apresenta comportamento químicomineralógico semelhante ao de uma argila do município de Itamarati de Minas, MG, a qual é utilizada numa indústria de cerâmica vermelha da região [20]. É importante destacar que o município de Itamarati de Minas, MG, é bem próximo ao município de Leopoldina, MG.

Pode ser observado que do ponto de vista químico (Tabela 2), o resíduo de ETA estudado é constituído basicamente por $\mathrm{SiO}_{2}, \mathrm{Al}_{2} \mathrm{O}_{3}$ e $\mathrm{Fe}_{2} \mathrm{O}_{3}$ que correspondem a cerca de $77,17 \%$. Este resultado está de acordo com alguns trabalhos abordados na literatura $\left[\underline{1}, \underline{2}, \underline{6}, \underline{10}, \underline{15}, \underline{18}\right.$, nos quais constam que os óxidos $\mathrm{SiO}_{2}$, $\mathrm{Al}_{2} \mathrm{O}_{3}$ e $\mathrm{Fe}_{2} \mathrm{O}_{3}$ são os principais óxidos presentes nos lodos de ETA estudados. O conteúdo de $\mathrm{SiO}_{2}$ pode estar relacionado com a presença de caulinita $[\underline{1}, \underline{10}]$. O elevado teor de alumina $\left(\mathrm{Al}_{2} \mathrm{O}_{3}\right)$ pode estar associado á presença de gibsita (hidróxido de alumínio - $\mathrm{Al}(\mathrm{OH})_{3}$ ) proveniente, principalmente, da reação do sulfato de alumínio, floculante, quanto da caulinita presente no resíduo $[1,10,15]$. O elevado teor de óxido de ferro $\left(\mathrm{Fe}_{2} \mathrm{O}_{3}\right)$ apresentado pelo resíduo pode ser devido a presença de hematita e de goetita (hidróxido de ferro $\mathrm{FeO}(\mathrm{OH})$ ). Os teores de $\mathrm{MnO}$ e $\mathrm{TiO}_{2}$ são relativamente baixos. Os teores de óxidos alcalinos $\left(\mathrm{K}_{2} \mathrm{O}\right.$ e $\left.\mathrm{Na}_{2} \mathrm{O}\right)$ e alcalinos terrosos $(\mathrm{MgO}$ e $\mathrm{CaO})$ são baixíssimos. Estes óxidos podem estar associados a impurezas presentes como cátions trocáveis na estrutura dos argilominerais [1]. A perda ao fogo do resíduo é relativamente alta, da ordem de 19,32\%. Esta perda ao fogo pode estar relacionada principalmente com a presença de argilominerais (caulinita), hidróxidos e matéria orgânica [10].

Pode ser observado a partir da Tabela 3 que as partículas do resíduo, praticamente, em quase sua totalidade, apresentam um tamanho de partícula $<63 \mu \mathrm{m}$. Na Figura 3 pode ser observado que de forma geral o resíduo apresenta um aspecto arenoso, sendo constituído por uma grande quantidade de partículas muito finas, as quais formam aglomerados maiores. Isto pode estar relacionado com a elevada energia de superfície específica das partículas finas. De acordo com a Tabela 3 e com a Figura 3, provavelmente, o resíduo estudado apresenta uma grande quantidade de partículas com tamanho situado na faixa $<2 \mu \mathrm{m}$ (fração argila).

O resíduo estudado apresentou um valor de massa específica real (MER) da ordem de 2,58 g/ $\mathrm{cm}^{3}$ (Ta- 
bela 4). Este valor está dentro da faixa para materiais argilosos [2] . Neste trabalho a plasticidade do resíduo (lodo) de ETA foi medida e caracterizada através da determinação do índice de plasticidade de Atterberg (IPA), o qual é a diferença entre o limite líquido $\left(\mathrm{L}_{1}\right)$ e o limite plástico $\left(\mathrm{L}_{\mathrm{p}}\right)$. A determinação da plasticidade é de grande importância, visto que a extrusão, a qual é um dos principais processos de conformação utilizados na indústria de cerâmica vermelha, tem o rendimento e a qualidade dos produtos finais afetados por vários fatores, entre eles, a plasticidade das massas argilosas utilizadas [21]. Pode ser observado na Tabela 4 que o resíduo apresentou $\mathrm{L}_{\mathrm{p}}$ de $49 \%, \mathrm{~L}_{1}$ de $71 \%$ e IPA de $22 \%$. Com base em dados de literatura [22], verifica-se que o valor de IPA obtido está dentro do intervalo observado para cerâmica vermelha $(10<\operatorname{IPA}<30)$, podendo ser considerado, de acordo com [23], altamente plástico (IPA > 15\%). O elevado valor do índice de plasticidade pode estar relacionado principalmente com a presença de argilomineral (caulinita) e matéria orgânica []]. Isto indica que o resíduo estudado pode ser usado em massas argilosas para cerâmica vermelha. Entretanto, o resíduo apresentou um valor de $\mathrm{L}_{\mathrm{p}}$ acima da faixa recomendada para cerâmica vermelha (15 $30 \%$ ) [22]. Isto pode indicar que a incorporação do resíduo em massas argilosas para cerâmica vermelha pode acarretar problemas, principalmente, durante o processo de secagem dos produtos cerâmicos, tais como alta retração e defeitos (trincas). Apesar disso, o resíduo estudado pode ser utilizado em quantidades moderadas [2].

\section{CONCLUSÕES}

Os resultados obtidos indicam que o resíduo (lodo) de ETA proveniente do município de Leopoldina, MG, apresenta grande potencial para ser incorporado em massas argilosas para a fabricação de produtos de cerâmica vermelha. Do ponto vista mineralógico o resíduo é constituído pelo argilomineral caulinita e por hematita. Do ponto de vista químico, o resíduo é rico em $\mathrm{SiO}_{2}, \mathrm{Al}_{2} \mathrm{O}_{3}$ e $\mathrm{Fe}_{2} \mathrm{O}_{3}$. Com base nestes resultados foi observado que o resíduo apresenta um comportamento químico-mineralógico semelhante ao de uma argila proveniente do município de Itamarati de Minas, MG. Município este, que é próximo ao município de Leopoldina, MG. Do ponto de vista físico, o resíduo apresentou um aspecto arenoso, formado em quase sua totalidade por partículas muito finas (granulometria abaixo da fração $<63 \mu \mathrm{m}$ ), sendo um material plástico com IPA = $22 \%$. Valor este que se encontra dentro da faixa recomendada para cerâmica vermelha. Entretanto, é aconselhável que este resíduo seja incorporado às massas argilosas usadas na indústria de cerâmica vermelha em quantidades moderadas devido ao seu elevado valor de limite plástico.

\section{AGRADECIMENTOS}

Os autores agradecem as Faculdades Integradas de Cataguases - Grupo UNIS (FIC/UNIS) e a Universidade do Estado de Minas Gerais - Unidade de Ubá (UEMG/Ubá) pelo suporte técnico.

\section{BIBLIOGRAFIA}

[1] VIEIRA, C.M.F., MARGEM, J.I., MONTEIRO, S.N., “Alterações microestruturais de cerâmica argilosa incorporada com lodo de ETA”, Revista Matéria, v. 13, n. 2, pp. 275-281, 2008.

[2] OLIVEIRA, E.M.S., MACHADO, S.Q., HOLANDA, J.N.F., "Caracterização de resíduo (lodo) de estação de tratamento de águas visando sua utilização em cerâmica vermelha”, Cerâmica, v. 50, n. 316, pp. 324330, Out/Dez. 2004.

[3] BOTERO, W.G., SANTOS, A., OLIVEIRA, L.C., et al; "Caracterização de lodo gerado em estações de tratamento de água: Perspectivas de aplicação agrícola”, Química Nova, v. 32, pp. 2018-2022, 2009.

[4] PAIXÃO, L.C.C., YOSHIMURA, H.N.; ESPINOSA, D.C.R., et al; "Efeito da incorporação de lodo de ETA contendo alto teor de ferro em cerâmica argilosa”, Cerâmica, v. 54, n. 329, pp. 63-76, Mar. 2008.

[5] Editoria, PROJETO PREPARATÓRIO PARA O GERENCIAMENTO DE RECURSOS HÍDRICOS DO PARAÍBA DO SUL, www.hidro.ufrj.br. Acessado em Janeiro de 2014.

[6] RODRIGUES, L.P., HOLANDA, J.N.F., "Influência da incorporação de lodo de estação de tratamento de água (ETA) nas propriedades tecnológicas de tijolos solo-cimento”, Cerâmica, v. 59, n. 352, pp. 551-556, Dez. 2013.

[7] TARTARI, R., DIAZ-MORA, N., MONDÉNES, A.N., et al., "Lodo gerado na estação de tratamento de água Tamanduá, Foz do Iguaçú, PR, como aditivos em argila para cerâmica vermelha. Parte I: Caracterização do lodo e de argilas do terceiro planalto paranaense", Cerâmica, v. 57, n. 343, pp. 288-293, Set. 2011. 
[8] TEIXEIRA, S.R., SOUZA, S.A., SOUZA, N.R., et al., "Efeito da adição de lodo de estação de tratamento de água (ETA) visando nas propriedades de material cerâmico estrutural", Cerâmica, v. 52, n. 323, pp. 215220, Set. 2006.

[9] HOPPEN, C., PORTELLA, K.F., JOUKOSKI, A., et al., "Co-disposição de lodo centrifugado de Estação de Tratamento de Água (ETA) em matriz de concreto: método alternativo de preservação ambiental" Cerâmica, v. 51, n. 318, pp. 85-95, Jun. 2005.

[10] SOUZA, V.P., TOLEDO, R., HOLANDA, J.N.F., et al; "Análise dos gases poluentes liberados durante a queima de cerâmica vermelha incorporada com lodo de estação de tratamento de água", Cerâmica, v. 54, n. 331, pp. 351-355, Set. 2008.

[11] SANTOS, R.S., SOUZA, G.P., HOLANDA, J.N.F., "Caracterização de massas argilosas contendo resíduo do setor petrolífero e sua utilização em cerâmica estrutural", Cerâmica, v. 48, n. 307, pp. 115-120, Set. 2002.

[12] BALATON, V.T., GONÇALVES, P.S., FERRER, L.M., "Incorporação de resíduos sólidos galvânicos em massas de cerâmica", Cerâmica Industrial, v. 7, n. 6, pp. 42-45, Nov/Dez. 2002.

[13] FERNANDES, P.F., OLIVEIRA, A.P.N., HOTZA, D., "Incorporação de resíduos sólidos galvânicos em massas de cerâmica", Cerâmica Industrial, v. 8, n. 2, pp. 26-34, Mar/Abr. 2003.

[14] MENEZES, R.R., NEVES, G.A., FERREIRA, H.C., "O estado da arte sobre o uso de resíduos como matérias-primas cerâmicas alternativas", Rev. Brás. Eng. Ambiente., v. 6, n. 2, pp. 303-313, 2002.

[15] VITORINO, J.P.D., MONTEIRO, S.N., VIEIRA, C.M.F., "Caracterização e incorporação de resíduos provenientes de estação de tratamento de água em cerâmica argilosa", Cerâmica, v. 55, n. 336, pp. 385-392, Dez. 2009.

[16] OLIVEIRA, E.M.S., HOLANDA, J.N.F., "Influência da adição de resíduo (lodo) de estação de tratamento de águas nas propriedades e microestrutura de cerâmica vermelha", Cerâmica, v. 54, n. 330, pp. 167173, Jun. 2008.

[17] MORUZZI, R.B., FERRARI, T.N., "Incorporação do lodo gerado na estação de tratamento de água (ETAII) do município de Rio Claro-SP em argila utilizada para a produção de cerâmica vermelha", In: Encontro de Engenharia e Tecnologia dos Campos Gerais, $4^{\circ}$, pp. 1-11, Ponta Grossa, Agost. 2008.

[18] HOPPEN, C., PORTELLA, K.F., JOUKOSKI, A., et al; "Uso de lodo de estação de tratamento de água centrifugado em matriz de concreto de cimento portland para reduzir impacto ambiental", Química Nova, v. 29, n. 1, pp. 79-84, 2006.

[19] SANTOS, P.S., Ciência e Tecnologia de Argilas, v. 1, 2 ed., São Paulo, EdigardBlucherLtda, 1989.

[20] PINHEIRO, B.C.A., PINHEIRO, E.F., SOUZA, S.F., "Caracterização químico-mineralógica de uma amostra de argila utilizada em uma indústria cerâmica da região de Itamarati de Minas-MG", In: $57^{\circ} \mathrm{Con}$ gresso Brasileiro de Cerâmica \& $5^{\circ}$ Congresso Iberoamericano de Cerâmica,pp. 10-15,Natal, Maio. 2013.

[21] RIBEIRO, M.J., FERREIRA, A.A.L., LABRINCHA, J.A., "Aspectos fundamentais sobre a extrusão de massas de cerâmica vermelha", Cerâmica Industrial, v. 8, n. 1, pp. 37-42, Jan/Fev. 2003.

[22] MACEDO, R.S., MENEZES, R.R., NEVES, G.A., et al., "Estudo de argilas usadas em cerâmica vermelha", Cerâmica, v. 54, n. 332, pp. 411-417, Dez. 2008.

[23] CAMPOS, L.F.A., MACEDO, R.S., KYOHARA, P.K., et al., "Características de plasticidade argilas para uso em cerâmica vermelha ou estrutural”, Cerâmica, v. 45, n. 295, pp. 1-10, Maio. 1999. 